\title{
Partial withdrawal of deeply inserted cochlear electrodes: observations of two patients
}

\author{
Maria-Izabel Kos $\cdot$ Colette Boex $\cdot$ Jean-Philippe Guyot $\cdot$ \\ Marco Pelizzone
}

Received: 1 June 2006 / Accepted: 14 May 2007 / Published online: 12 June 2007

(C) Springer-Verlag 2007

\begin{abstract}
Three patients implanted in our department received the preformed Clarion S-Series cochlear implant with the electrode Positioning System (EPS). The EPS is a device designed to bring the electrode array closer to the modiolus and deeper into the cochlea. Two of these patients still complained because they were perceiving too low pitch sounds, and because of the presence of echoes and poor discrimination after 3 years of implant use and many tuning sessions. We hypothesized that the electrode array was too deeply inserted and could be stimulating overlapping populations of neurons in the low frequency range. The EPS was removed through a transcanal tympanotomy under local anesthesia and the array was pulled $2-3 \mathrm{~mm}$ out of the cochlea. The angle of electrode insertion into the cochlea and the patients' performances on consonant identification tests were evaluated before and after the removal surgery and over the long term, 3 years after the surgery. Immediately after the removal surgery the angle of insertion of the electrode array decreased from $720^{\circ}$ to $485^{\circ}$ in one case and from $675^{\circ}$ to $485^{\circ}$ in the other. Both patients reported subjective improvements after the removal which were confirmed by tests of performance at the long term by one of the patients. These observations show that (1) the electrode array can be moved without deterioration of performances even several years after being implanted; revision surgery may be beneficial in some cases, (2) neighboring electrodes
\end{abstract}

M.-I. Kos · C. Boex · J.-P. Guyot · M. Pelizzone

Department of Otolaryngology, Head and Neck Surgery,

University Hospitals of Geneva, 1211 Geneva 14, Switzerland

M.-I. Kos ( $\square)$

ENT Department, Geneva University Hospital, 24 Micheli-du-Crest, 1211 Geneva 14, Switzerland

e-mail: izabel.kos@hcuge.ch might stimulate overlapping populations of neurons, inducing a deterioration of performances; for anatomical reasons, this is most likely to occur in the apex of the cochlea and (3) tuning of the external processor should be a customized procedure.

Keywords Cochlear implants · Electrode location · Electrode interaction $\cdot$ Hearing performance

\section{Introduction}

Cochlear implants transform sounds in electric signals that are distributed among the many electrodes inside the cochlea. The distribution of the electric signals respect the tonotopic specificity of the sensory structures of the cochlea: low frequency signals are sent to electrodes in the apex and high frequency signals to the electrodes in the base of the cochlea. One of the trends in research is to develop electrodes that could help improve the quality and efficacy of the electric signal delivered to the nerve fibers or the ganglion cells [1-6]. In 1999 one producer proposed a device that could push the array closer to the modiolus and as a consequence, deeper into the cochlea. The electrode Positioning System (EPS) is an independent silicone part designed to be introduced into the cochlea, between the electrode array and the outer wall [7]. This would allow a more precise stimulation with lower levels of electrical current. In our series of implanted patients only three received such a device with the preformed Clarion S-Series electrode [8]. This study reports that in two of these three cases this system was disadvantageous. Results of speech performance improved after partial withdrawal of the electrode array out of the cochlea that was done with the removal of the EPS. 


\section{Materials and methods}

Patients

The two patients had a similar history. They had lost their hearing, first on the left as a result of idiopathic sudden hearing loss. In the following years they suffered from several episodes of vertigo and progressive hearing loss, because of contralateral idiopatic delayed hydrops. Both patients received the Clarion S-Series with EPS on the left. The processor was secured to the mastoid bone. A mastoidotomy was performed and the electrode array was introduced into the middle ear and inside the cochlea through a posterior tympanotomy. The Clarion S-Series array and the EPS were sequentially inserted into the cochlea with the appropriate insertion tools [9]. The cochleostomy was then tightly sealed with a plug of temporalis fascia.

Measure of the angle of insertion of the electrode array was done with a postoperative radiography with a modified Stenver's view X-ray described by Marsh et al. [10]. The location of the round window was determined on the basis of a method described elsewhere [11-13]. Briefly it consists in localizing the round window, using two reference points: the apex of the superior semi-circular canal and the center of the vestibule. The round window site corresponds to the intersection of the array by a straight line connecting these two points. From the site of the round window the insertion angle of the most apical electrode of the array was measured. Hearing performances were evaluated using consonant identification tests without visual cues as described elsewhere [14]. The mean percent of correct initial consonant
(IC) identification was calculated through at least six presentations gathered within two different sessions.

EPS removal and partial withdrawal of electrode array was done 46 months after the implantation for patient 1 and 30 months after the implantation for patient 2. Operations were done under local anesthesia through a transcanal tympanotomy. Fibrous tissue was dissected until the cochleostomy was completely exposed and the electrode array and the EPS were visible. The electrode array was secured in place and the EPS pulled out completely. The electrode array was withdrawn 2-3 $\mathrm{mm}$ out of the cochlea and placed against the outer wall of the cochlea, under the surgeon's visual control. The cochleostomy was again tightly sealed with a plug of temporalis fascia.

\section{Results}

Measure of the angle of insertion

After cochlear implantation for patient 1 the insertion angle of the electrode array was $720^{\circ}$ and for patient $2,675^{\circ}$ (Fig. 1a). After partial withdrawal of electrode array and removal of the EPS the insertion angles decreased for patient 1 from $720^{\circ}$ to $485^{\circ}$ and for patient 2 from $675^{\circ}$ to $433^{\circ}$ (Fig. 1b).

\section{Hearing performances}

After cochlear implantation both patients started using their speech processors with a program including all eight
Fig. 1 Position of electrode array inside the cochlea a before and $\mathbf{b}$ after partial withdrawal of the electrode array and removal of the EPS

\section{Before withdrawal} With EPS

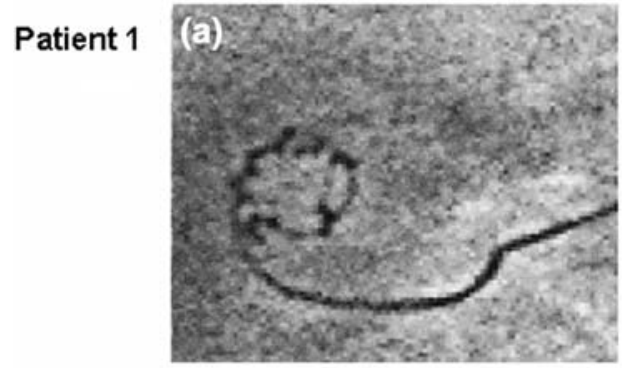

(a)

Patient 2

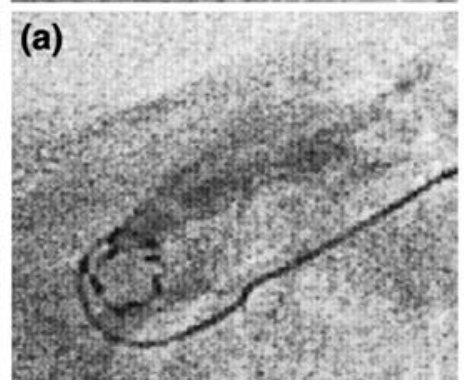

\section{After withdrawal Without EPS}

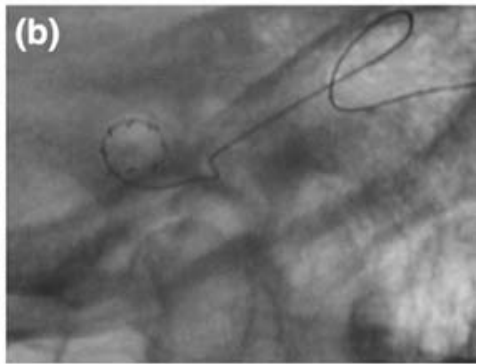

(b) 
electrodes. Patient 1 was able to give $31 \%$ of correct answers in the IC test after having worn the implant for 46 months and patient 2, $51 \%$ after 30 months. Subjectively both patients complained consistently of perceiving sounds with a very low pitch quality and of the presence of echoes. They had their processors switched to a program of six electrodes with the two most apical electrodes being turned off. This procedure resulted in an objective improvement in their performances $(P>0.05)$ (Table 1). Patient 2 subjectively described a reduction in the echoes perceived.

After partial withdrawal of the electrode array and removal of EPS, both patients adopted an eight-electrode strategy. In the long term ( 3 years) the performances deteriorated for patient 1 and significantly improved for patient 2 $(P<0.05)$. Patient 1 cannot concentrate during long test sessions (Table 1).

Both patients say that the perceived sounds have more high pitches, they hear without echoes and wear their implants daily.

\section{Discussion}

Cochlear implants allow totally deaf adults to recover speech discrimination [15]. The development of such devices is the result of a close collaboration between research and clinical groups. A few years ago, in an effort to improve the performances of implanted patients, a new electrode array was developed. The two cases reported here indicate that such improvements are not always beneficial to patients. In both cases, following fabricant's recommendations the electrode arrays were implanted deeply and placed closer to the modiolus if compared to another series of implanted patients with insertion angles ranging from $270^{\circ}$ to $756^{\circ}$ [11]. These two patients complained of the predominantly low pitch quality of the perceived sounds. That was probably related to the too deep position of the electrodes inside the cochlea. Their performance tests showed worse results when the most apical electrodes were in use and were significantly better when they were turned off. Both patients had the electrode array partially withdrawn from the cochlea as a result of the removal of the EPS. This resulted in a more basal location of the electrodes. After that, both patients started to use again

Table 1 Hearing performances

\begin{tabular}{llll}
\hline & \multicolumn{2}{l}{$\begin{array}{l}\text { Before withdrawal } \\
\text { with EPS }\end{array}$} & $\begin{array}{l}\text { After withdrawal } \\
\text { without EPS }\end{array}$ \\
\cline { 2 - 3 } & Eight eletrodes & Six eletrodes & Eight electrodes \\
\hline Patient 1 & $31 \%$ (SD 8.45) & $37 \%$ (SD 5.08) & $23 \%$ (SD 4.71) \\
Patient 2 & $51 \%$ (SD 5.52) & $59 \%$ (SD 3.77) & $66 \%$ (SD 8.99) \\
\hline
\end{tabular}

Initial consonant test eight electrodes and informed that the sounds perceived had less low pitch quality. One of them also showed an improvement in his speech performance over the long term. Even many years after implantation the electrode array can be moved without compromising the user's performance.

The studied patients suffered from sudden deafness [16] followed some years later by contralateral idiopathic delayed hydrops in which progressive hearing loss and vertigo are main features. Schuknecht [17] analysed the temporal bones of patients who had suffered of contralateral idiopathic delayed hydrops. In the first deaf ear he observed an atrophy of the organ of Corti and a retrograde degeneration of the dendrites and of the ganglion cells. In such cases the electric current generated by the cochlear implant travels over a certain distance between the electrodes inside the scala tympany and the ganglion cells. It is a risk that an undesired spread of current stimulates different groups of neurons, generating confusions and a loss in discrimination. This risk is higher at the apex of the cochlea where the neurons are concentrated. These observations are in agreement with the experimental study of Briaire et al. in which they discuss that the usual position of the electrodes inside the scala tympany aimed to be as close as possible to the modiolus can be satisfactory in cases were there is dendrite preservation but might not be ideal in cases of dendrite degeneration, where the spatial selectivity is limited, mainly in the apex due to the cross turn stimulation [18]. Furthermore, Boex et al. [19] observed, in a study of six implanted patients that electrical stimulation elicited pitch perceptions that were lower than those expected from the site of stimulation, according to Greenwoods' function [20] and according to what was perceived acoustically by the same patients through the residual hearing of the contra-lateral ear. These authors suggest that the electrical excitation might not activate the nerve fibres according to the tonotopic organisation of the organ of Corti but could excite directly the ganglion cells. In this case, cross turn stimulation is possible due to the packing of the cells inside the modiolus. That could be even more critical in the apex of the cochlea at the helicotrema. The hypothesis that an interaction between electrodes could be the cause of our patients' complaints was developed following the observation of the third patient who have received the same system. This patient, who lost his hearing after a treatment with streptomycin, received the same cochlear implant with the EPS. In cases of streptomycin ototoxicity there would be less risk of interactions because there is degeneration of hair cells but the dendrites and ganglion cells are relatively preserved [21]. In spite of the fact that this patient has a very deep electrode insertion, comparable to the initial depth observed in the two studied cases, he perceives high pitch tones, and his performance is of $60.5 \%$ (SD 2.12) of correct responses in the IC test. 
As for hearing aids, cochlear implants are usually sold in packages that include standardised tuning programs. This material is intended to facilitate the tuning of the external processor of cochlear implants, making it possible to be done by a large number of professionals. This is broadly done but unfortunately at the price of more cases of nonoptimal utilisations of the device. To obtain optimal results with cochlear implants, the tuning procedure has to be extensively adapted, electrode after electrode, to each individual patient. The two cases reported here show that the complaints of patients can be confirmed with specific tests and that the tuning of the processor cannot be treated as a standard procedure. This tuning requires a multidisciplinary team of engineers, surgeons, physicians and audiologists with knowledge of the anatomy and physiology of the hearing system as well as of the implications of the electrical stimulation. It seems reasonable to limit the adaptation of cochlear implants to clinical centres having a multidisciplinary team collaborating closely with research teams.

\section{Conclusions}

These observations show that (1) the electrode array can be moved without deterioration of performances even several years after being implanted; revision surgery may be beneficial in some cases, (2) neighboring electrodes might stimulate overlapping populations of neurons, inducing a deterioration of performances; for anatomical reasons, this is most likely to occur in the apex of the cochlea and (3) tuning of the external processor should be a customized procedure.

\section{References}

1. Hodges AV, Villasuso E, Balkany T, Bird PA, Butts S, Lee D, Gomez O (1999) Hearing results with deep insertion of cochlear implant electrodes. Am J Otol 20(1):53-55

2. Saunders E, Cohen L, Aschendorff A, Shapiro W, Knight M, Stecker M, Richter B, Waltzman S, Tykocinski M, Roland T, Laszig R, Cowan R (2002) Threshold, comfortable level and impedance changes as a function of electrode-modiolar distance. Ear Hear 23(1S):28S-40S
3. Watts SJ, Lindsey P, Hawthorne M (2000) Medialization of electrode array in cochlear implantation. J Laryngol Otol 114:746-749

4. Fayad JN, Luxford W, Linthicum FH (2000) The Clarion electrode positioner: temporal bone studies. Am J Otol 21:226-229

5. Richter B, Aschendorff A, Lohnstein P, Husstedt H, nagursky H, Laszig R (2001) The nucleus contour electrode array: a radiological and histological study. Laryngoscope 111:508-514

6. Hochmair I, Wolfgang A, Nopp P, Jolly C, Müller J, Roland P (2003) Deep electrode insertion in cochlear implants: apical morphology, electrodes and speech reception results. Acta Otolaryngol 123:612-617

7. Kuzma JA, Balkany TJ (1999) New generation Clarion electrodes for highly focused stimulation. Conference on implantable auditory prostheses. Proceedings, p 60. Asilomar, CA, USA, August 29-September 3, 1999

8. Kessler D (1999) The Clarion ${ }^{\circledR}$ multi-strategy cochlear implant. Ann Otol Rhinol Laryngol 108:8-18

9. Balkany T, Cohen N, Gantz B (1999) Surgical technique for the Clarion cochlear implant. Ann Otol Rhinol Laryngol 108: 27-30

10. Marsh MA, Xu J, Blamey PJ, Whitford LA, Xu SA, Silverman JM, Clark GM (1993) Radiologic evaluation of multichannel intracochlear implant insertion depth. Am J Otol 14:386-391

11. Kós MI, Boëx C, Sigrist A, Guyot JP, Pelizzone M (2005) Insertion depths of different types of cochlear implants. Acta Otolaryngol 125:474-480

12. Cohen LT, Xu J, Clark G (1996) Improved and simplified methods fr specifying positions of the electrode bands of a cochlear implant array. Am J Otol 17:859-865

13. Xu J, Xu SA, Cohen LT, Clerk G (2000) Cochlear view: postoperative radiography for cochlear implantation. Am J Otol 21:49-56

14. Pelizzone M, Boex C, Montandon P (1993) Vowels and consonants identification tests can be used to compare performances in a multilingual group of cochlear implant patients. ORL 55:341345

15. Waltzman SB, Cohen NL, Shapiro WH (1993) The benefits of cochlear implantation in the geriatric population. Otolaryngol Head Neck Surg 108:329-333

16. Schuknecht HF, Kimura RS, Naufal PM (1973) The pathology of sudden deafness. Acta Otolaryngol 76:75-97

17. Schuknecht HF, Suzuka Y, Zimmermann C (1990) Delayed endolymphatic hydrops and its relationship to Menière's disease. Ann Otol Laryngol 99:843-853

18. Briaire J, Frijns J (2006) The consequences of neural degeneration regarding optimal cochlear implant position in scala tympani: a model approach. Hear Res 214:17-27

19. Boex C, Baud L, Cosendai G, Sigrist A, Kos MI, Pelizzone M (2006) Acoustic to electric pitch comparisons in cochlear implant subjects with residual hearing. J Assoc Res Otolaryngol 7:110124

20. Greenwood DD (1990) A cochlear frequency-position for several species-29 years later. J Acoust Soc Am 87(6):2592-2605

21. Schuknecht HF (1993) Disorders of intoxication. Pathology of the ear, 2nd edn. Lea \& Febiger, Philadelphia 